Research article

urn:1sid:zoobank.org:pub:5F88C22D-0A1D-4BBB-A858-C0199866A63A

\title{
Yuelushannus gen. nov. (Araneae, Linyphiidae) from China
}

\author{
Muhammad IRFAN ${ }^{1}$, Gu-chun ZHOU ${ }^{2}$, Shahida BASHIR ${ }^{3}$, \\ Muhammad Khalid MUKHTAR ${ }^{4} \&$ Xian-jin PENG ${ }^{5, *}$ \\ ${ }^{1,5}$ College of Life Sciences, Hunan Normal University, Changsha, Hunan 410081, China. \\ ${ }^{1}$ College of Medicine, Shenzhen University, Shenzhen 518060, Guangdong, China. \\ ${ }^{2}$ College of life Sciences, National Navel Orange Engineering Research Center, \\ Gannan Normal University, Ganzhou 341000, Jiangxi, China. \\ ${ }^{3}$ Departement of Zoology, Government Postgraduate College, Jhang 35200, Punjab, Pakistan. \\ ${ }^{4}$ Department of Zoology, University of Sargodha, Sargodha 40100, Punjab, Pakistan. \\ *Corresponding author: xjpeng@126.com \\ ${ }^{1}$ Email: irfanuos94@yahoo.com \\ 2Email: zhguch_23@163.com \\ ${ }^{3}$ Email: sbgcj@yahoo.com \\ ${ }^{4}$ Email: mkmukhtar@gmail.com

\footnotetext{
${ }^{1}$ urn:lsid:zoobank.org:author:4EE226DB-D810-4907-A4B6-B04F4E4241AB

${ }^{2}$ urn:1sid:zoobank.org:author:3150107F-0EFF-4146-B374-82FC476ADB0D

${ }^{3}$ urn:1sid:zoobank.org:author:FACFE77D-08BE-4790-A853-9212BA61F4ED

${ }^{4}$ urn:lsid:zoobank.org:author:23E57D15-5E6A-4244-9F99-CBEE59790B06

${ }^{5}$ urn:1sid:zoobank.org:author:5CF67046-FAB4-43F1-AA72-ED2EB9741CD9
}

\begin{abstract}
The new erigoninae genus Yuelushannus gen. nov. with two new species, Y. alatus sp. nov. ( $\hat{0}$ ) and Y. barbatus sp. nov. ( $(\hat{T})$ ), are described from Hunan and Hubei Provinces. Detailed descriptions of somatic features and genitalic characters, photos of the habitus and copulatory organs, line drawings of copulatory organs and a distribution map are provided.
\end{abstract}

Keywords. Erigoninae, morphology, sheet web spiders, taxonomy, Yuelu Mountain.

Irfan M., Zhou G., Bashir S., Mukhtar M.K. \& Peng X. 2020. Yuelushannus gen. nov. (Araneae, Linyphiidae) from China. European Journal of Taxonomy 642: 1-17. https://doi.org/10.5852/ejt.2020.642

\section{Introduction}

The spider family Linyphiidae Blackwall, 1859 comprises $10 \%$ of all spiders, making it the second largest family with 4,613 species belonging to 613 genera worldwide (World Spider Catalog 2019). Li \& Lin (2016) listed 371 linyphiid species in 154 genera from China, including 74 species in 42 genera from Hubei and Hunan Provinces, out of which 172 species in 91 genera belong to the subfamily Erigoninae. While examining specimens collected from Hunan and Hubei Provinces, two new species belonging 
to an unknown genus were found. Yuelushannus gen. nov. and its new species are described. The type specimens are deposited in the College of Life Sciences, Hunan Normal University, Changsha, China.

\section{Material and Methods}

Specimens were collected by sieving leaf litter and were kept in $75 \%$ ethanol. After dissecting from the body, epigynes were cleared in trypsin solution before examination and photography. Left male palps were used for descriptions and illustrations. Specimens were examined and measured with a Leica M205C stereo microscope. Photos were taken with a digital camera (Canon PowerShot G12) mounted on an Olympus BX53 and with a Leica MC170 HD camera mounted on a Leica M205C, and stacked using Helicon Focus software (3.10). Maps were created in ArcMap 10.2 and then modified by using Adobe Photoshop CS2 Extended (Fig. 11). Leg measurements are given in the following order: total length (femur, patella + tibia, metatarsus, tarsus). All measurements are given in millimeters (mm). The terminology used in text and figure legends follows Hormiga (2000) and Zhao \& Li (2014).

\begin{tabular}{|c|c|c|}
\hline \multicolumn{3}{|c|}{ Abbreviations used in the text and figures: } \\
\hline AER & $=$ & anterior eye row \\
\hline ALE & $=$ & anterior lateral eyes \\
\hline alt. & $=$ & altitude \\
\hline AME & $=$ & anterior median eyes \\
\hline AME-ALE & $=$ & distance between AME and ALE \\
\hline AME-AME & $=$ & distance between AME \\
\hline ARP & $=$ & anterior radical process \\
\hline $\mathrm{CD}$ & $=$ & copulatory ducts \\
\hline DP & $=$ & dorsal plate \\
\hline DSA & $=$ & distal suprategular apophysis \\
\hline dTA & $=$ & dorsal tibial apophysis \\
\hline $\mathrm{E}$ & $=$ & embolus \\
\hline EM & $=$ & embolic membrane \\
\hline FD & $=$ & fertilization ducts \\
\hline $\mathrm{HN}$ & $=$ & Hunan \\
\hline HNDWS & $=$ & Hunan Daweishan \\
\hline HNU & $=$ & Hunan Normal University \\
\hline $\mathrm{PC}$ & $=$ & paracymbuim \\
\hline PER & $=$ & posterior eye row \\
\hline PLE & $=$ & posterior lateral eyes \\
\hline PME & $=$ & posterior median eyes \\
\hline PME-PLE & $=$ & distance between PME and PLE \\
\hline PME-PME & $=$ & distance between PME \\
\hline PT & $=$ & protegulum \\
\hline $\mathrm{R}$ & $=$ & radix \\
\hline $\mathrm{S}$ & $=$ & spermathecae \\
\hline SCS & $=$ & scapus \\
\hline SPT & $=$ & suprategulum \\
\hline ST & $=$ & subtegulum \\
\hline $\mathrm{T}$ & $=$ & tegulum \\
\hline Tm & $=$ & trichobothrium \\
\hline $\mathrm{TP}$ & $=$ & tail piece \\
\hline VP & $=$ & ventral plate \\
\hline YLS & $=$ & Yuelushan \\
\hline
\end{tabular}




\title{
Results
}

\author{
Class Arachnida Cuvier, 1812 \\ Order Aranae Clerck, 1757 \\ Family Linyphiidae Blackwall, 1859 \\ Yuelushannus gen. nov. \\ urn:Isid:zoobank.org:act:18108D03-0826-4EF0-BB3A-E90031CFD461
}

Figs 1-11

Type species: Yuelushannus barbatus sp. nov.

\section{Etymology}

The genus is named after the type locality (Yuelu) of the type species. Gender masculine.

\section{Diagnosis}

Male abdomen with two pairs of sigellae and distinct scutum at anterior two third. (Figs 6A-C, 7) as in Ceratinella Emerton, 1882 (Ono et al. 2009: figs 63-66). The new genus can be differentiated from other genera on the basis of the following characters. Male carapace modified, cephalic pits present, the ocular region with thick spines pointing away from each other. Male palp: distal end of tibia dorsally with two tongue-shaped apophyses, densely covered with teeth (Figs 6B, 7B); embolus simple, sclerotized, very long and thick (Figs 6A-C, 7); anterior radical process as long as embolus, with distal frayed end (Figs 6A-C, 7). Epigyne: dorsal plate with scapus (Figs 8-9) as in Paikiniana Eskov, 1992 (Zhao \& Li 2014: figs 75a-c, 76c-d); copulatory ducts column-shaped; spemathecae present at lateral sides of dorsal plate (Figs 8-9).

\section{Description}

BoDy. Small (1.75-1.9); male cephalic lobe and pits distinct, ocular area with thick spines; female palpal claw absent; AER slightly procurved, PER recurved; both male and female abdomen with four sigillae; tracheal system desmitracheate, with two trunks confined to abdomen. Chaetotaxy: 1-1-1-1. TmI 0.160.25 , TmIV 0.12-0.18; leg formula IV-I-II-III; legs yellow without obvious patterns.

Male palp (Figs 1-2, 6-7). Patella as long as tibia; tibia with one retrolateral and one dorsal trichobothrium, dorsally with two tongue-shaped apophyses, densely covered with teeth; paracymbium hookshaped; tegulum with long transparent protegulum; distal suprategular apophysis sclerotized, distal end curved, extending forward. Embolic division: tail piece long, slightly overlapping suprategulum; embolic membrane transparent, tapered towards tip; embolus long arc-shaped, distally connected with thick sclerotized anterior radical process, as long as embolus extending forward.

EpIGYNe (Figs 3-4, 8-9). Ventral plate concave, covered with thick spines; posterior margin of dorsal plate with scapus; copulatory openings between dorsal and ventral plate; copulatory ducts long, columnshaped; dorsolateral spermathecae separated by $2 / 3$ of their diameter; fertilization ducts small, extending mesally.

\section{Natural History}

Mainly lives under leaf litter layer of broad-leaved and shrubbery forest; breeding season from October through April; adapted to temperatures from $0^{\circ} \mathrm{C}$ to $39^{\circ} \mathrm{C}$.

\section{Distribution}

China (Hunan Provice, Fig. 11). 


\section{Yuelushannus alatus sp. nov.}

urn:lsid:zoobank.org:act:F99DDE92-46AE-48EE-BDAA-1CF11ECE3537

Figs $1-5,11$

\section{Etymology}

The species name comes from Latin adjective "alatus", meaning "winged" and refers to the ocular region with wing-like spines in the male.

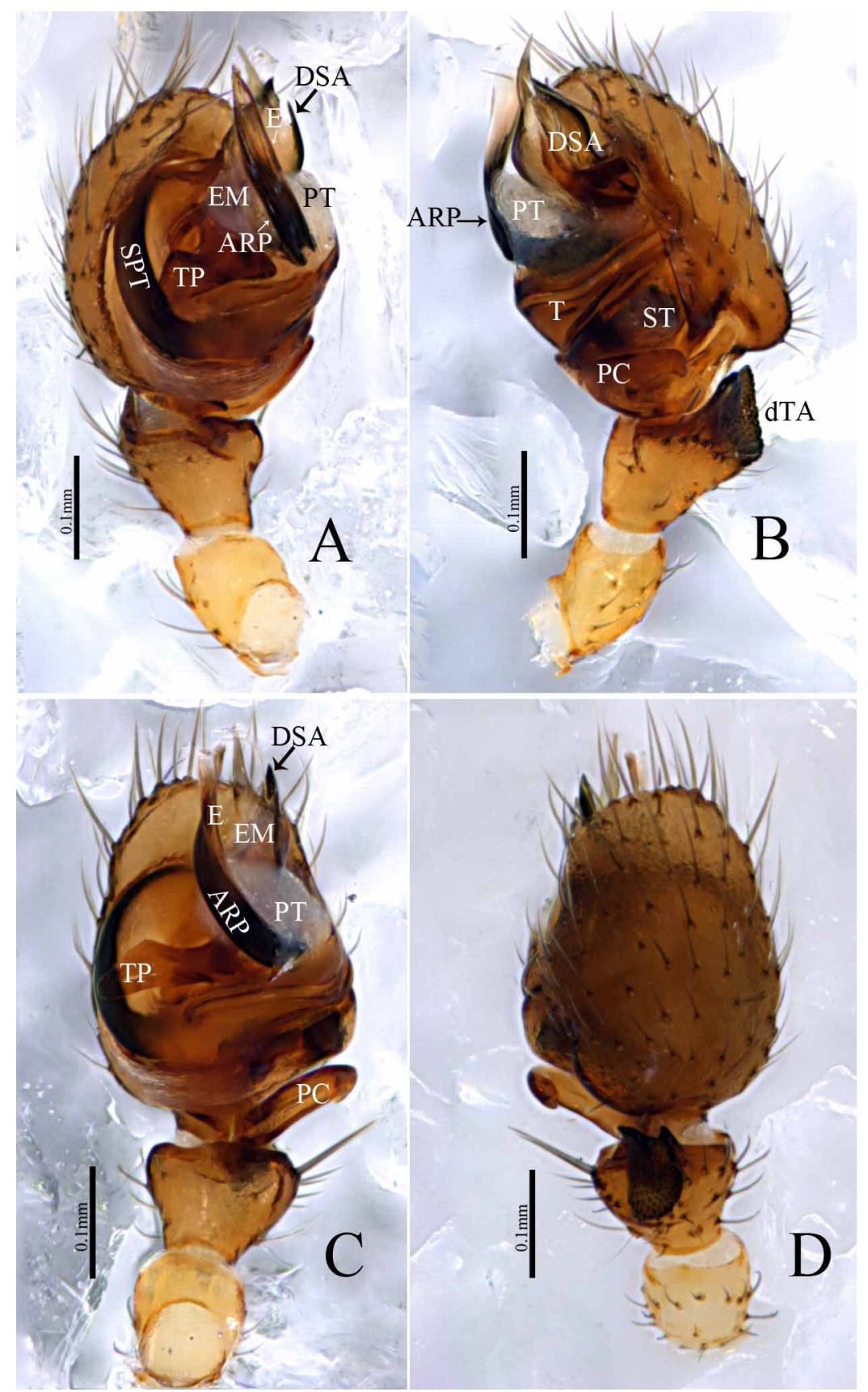

Fig. 1. Yuelushannus alatus sp. nov., male palp, holotype (HNDWS-18-04 01). A. Prolateral view. B. Retrolateral view. C. Ventral view. D. Dorsal view. Scale bars: $0.1 \mathrm{~mm}$. 


\section{Diagnosis}

This new species resembles Yuelushannus barbatus sp. nov. as two-thirds of the male abdomen has a very distinct scutum, the cephalic lobe and pits are distinct, both male and female abdomen with four sigillae. Tibial apophyses densely covered with teeth, paracymbium hook-shaped. Epigyne with column-shaped copulatory ducts. It can be distinguished by:

General: In male, ocular region with wing-like spines which covers most of PMEs in Y. alatus sp. nov. (Fig. 5E-G), whereas wing-like spines are absent in Y. barbatus sp. nov. (Fig. 10A-B).

Male: Tibial apophyses short, distal end about as long as broad in Y. alatus sp. nov. (Figs 1B, 2B), about four times as long as broad in Y. barbatus sp. nov. (Figs 6B, 7B). Protegulum short, retained below the distal suprategular apophysis in Y. alatus sp. nov. (Figs 1B, 2B), long, extending above the distal suprategular apophysis in $Y$. barbatus sp. nov. (Figs 6B, 7B). The distal suprategular apophysis long,

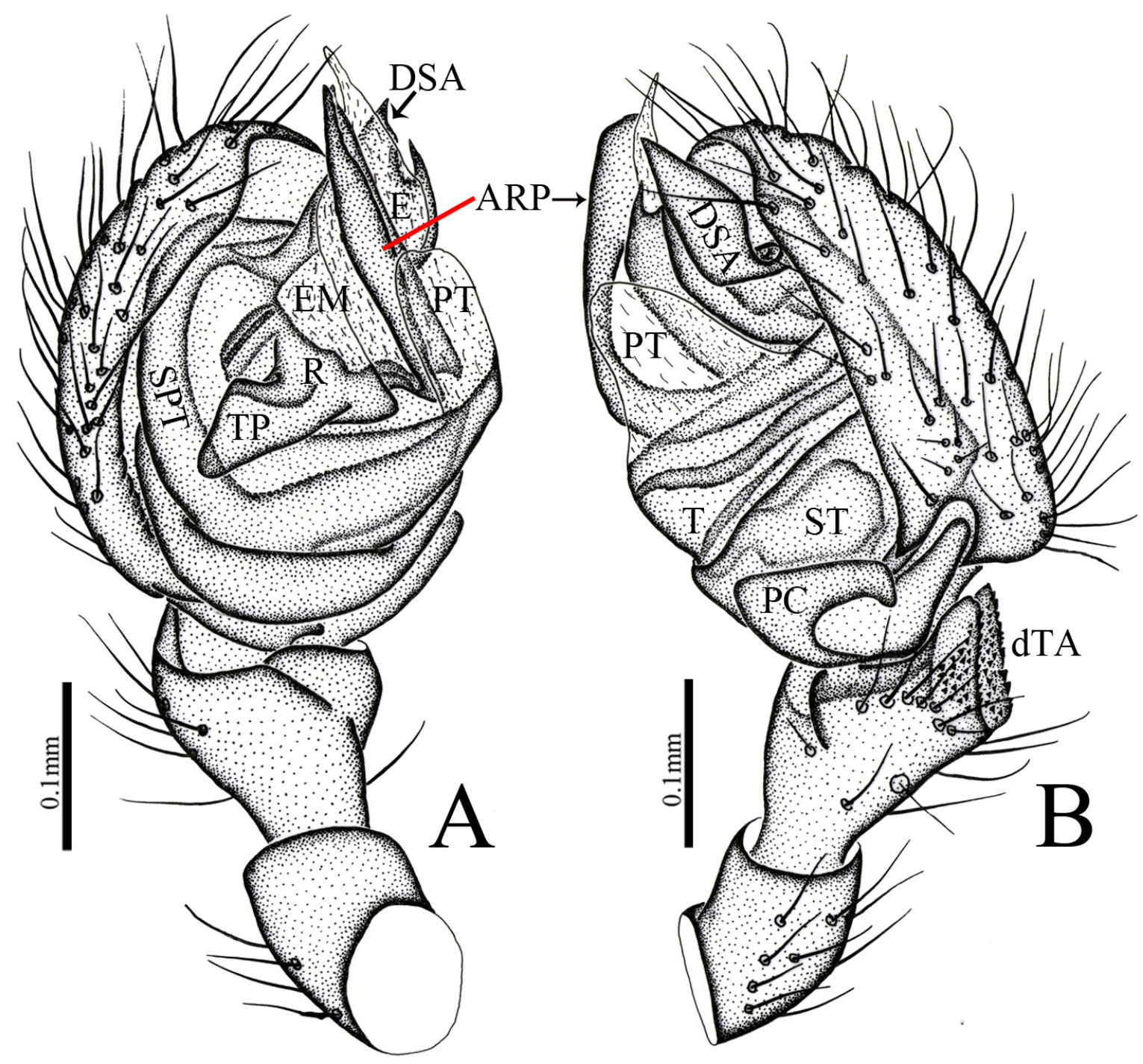

Fig. 2. Yuelushannus alatus sp. nov., male palp, holotype (HNDWS-18-04 01). A. Prolateral view. B. Retrolateral view. Scale bars: $0.1 \mathrm{~mm}$. 


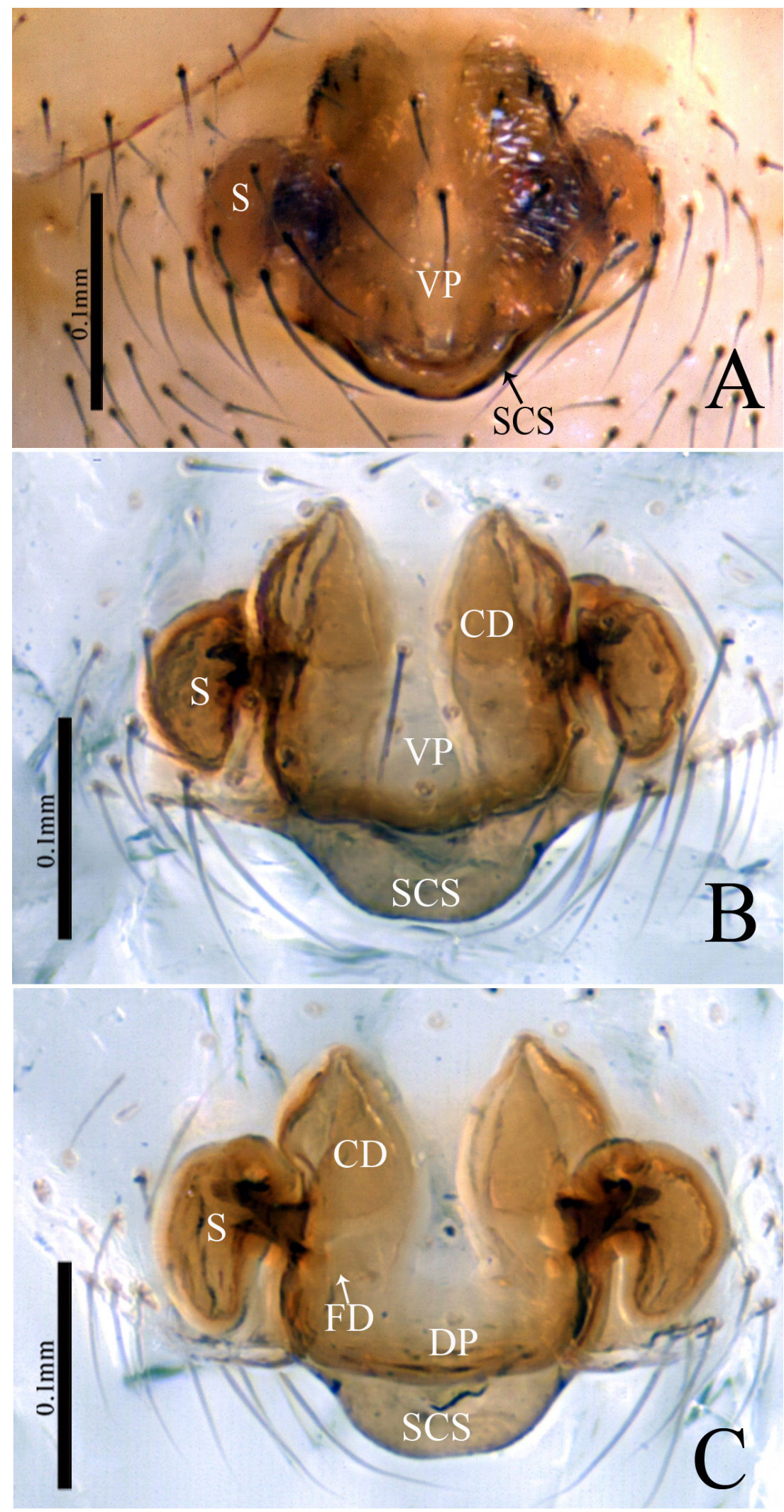

Fig. 3. Yuelushannus alatus sp. nov., female, allotype HNDWS-18-04 02. A. Epigyne, ventral view (before being dissected from the body). B. Epigyne, ventral view (after being dissected from the body). C. Vulva, dorsal view. Scale bars: $0.1 \mathrm{~mm}$. 
with bifurcated tip, extending above the apex of the cymbium in $Y$. alatus sp. nov. (Figs 1A-B, 2A-B), short, tip not bifurcated, retained below the apex of the cymbium in Y. barbatus sp. nov. (Figs 6A-B, 7). Distal end of anterior radical process not frayed in Y. alatus sp. nov. (Figs 1A-B, 2), whereas it is frayed in Y. barbatus sp. nov. (Figs 6A-B, 7).

Female: Spermathecae kidney-shaped in Y. alatus sp. nov. (Figs 3-4), globular in Y. barbatus sp. nov. (Figs 8-9).

\section{Holotype}

CHINA - Ō; Hunan Province, Liuyang City, Mudu Village, Dawei Mountain National Forest Park; $28.43567^{\circ} \mathrm{N}, 114.03376^{\circ}$ E; 14 Jan. 2018; alt. 286 m; Zhou Gu-chun, Wang Lu-yu and Liu Ke-ke leg.; HNU-HNDWS-18-04.

\section{Paratypes}

CHINA・2 $\widehat{\partial}, 2$ 우 ; same collection data as for holotype; HNU-HNDWS-18-04-02 05.
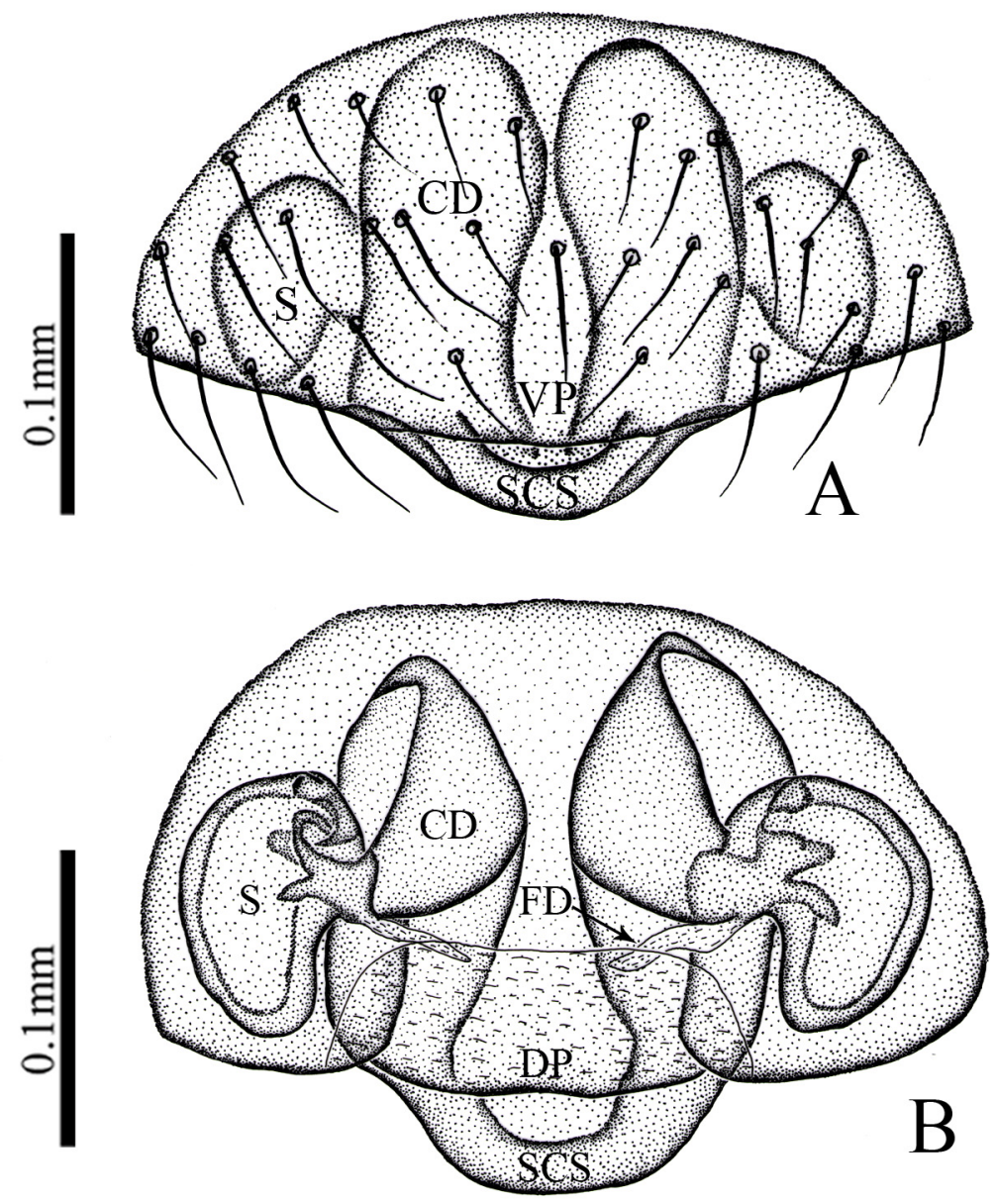

Fig. 4. Yuelushannus alatus sp. nov., female, allotype HNDWS-18-04 02. A. Epigyne, ventral view. B. Vulva, dorsal view. Scale bars: $0.1 \mathrm{~mm}$. 


\section{Description}

Male (holotype, HNU-HNDWS-18-04)

Body. Total length 1.85 , carapace 0.82 long, 0.71 wide, brown, cephalic lobe with distinct pits, ocular region with thick wing-like spines covering most of PMEs; fovea, cervical and radial grooves distinct; clypeus 0.23 high (Fig. 5A, E-G). Sternum wider than long, yellowish with spine-like hairs; labium wider than long; maxillae long, distal end broader, with scopulae (Fig. 5B). Chelicerae with six promarginal and five retromarginal teeth. Ocular region narrow, AER straight, PER procurved, PMEs present on cephalic lobe. Eye sizes and interdistances: AME 0.05; ALE 0.09; PME 0.06; PLE 0.07; AME-AME 0.02; PME-PME 0.05; AME-ALE 0.03; PME-PLE 0.05; AME-PME 0.10; ALE-ALE 0.32; PLE-PLE 0.33; ALE-PLE contiguous. Length of legs: I, 2.17 (0.65, 0.76, 0.44, 0.32); II, $1.9(0.59,0.67,0.38$, $0.26)$; III, $1.61(0.51,0.52,0.35,0.23)$; IV, $2.21(0.65,0.79,0.46,0.31)$. Leg formula IV-I-II-III. TmI 0.18 and TmIV 0.12. Tibial spine formula: $1-1-1-1$. Abdomen round, 1.15 long, 0.88 wide, two-thirds

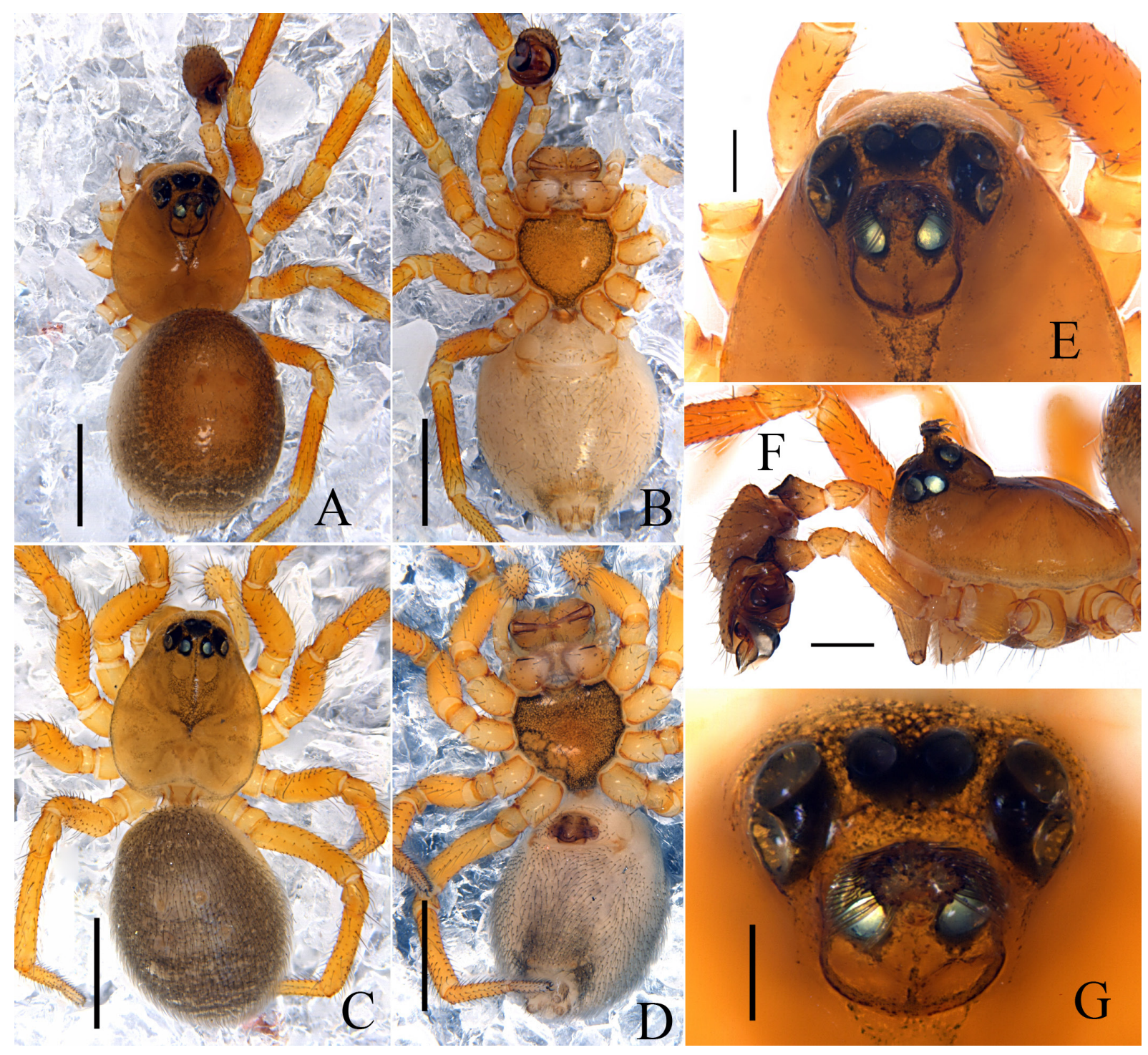

Fig. 5. Yuelushannus alatus sp. nov., male, holotype HNDWS-18-04 01 (A-B, E-F) and female allotype HNDWS-18-04 02 (C-D, G). A, C. Habitus, dorsal view. B, D. Habitus, ventral view. E, G. Cephalothorax, dorsal view. F. Habitus, lateral view. Scale bars: $A-D=0.5 \mathrm{~mm} ; \mathrm{E}, \mathrm{G}=0.1 \mathrm{~mm}$; $\mathrm{F}=0.2 \mathrm{~mm}$. 
of abdomen with distinct brown circle with four sigillae, lateral sides dusky grey, ventral side pale (Fig. $5 \mathrm{~A}-\mathrm{B})$.

Palp (Figs 1-2). Patella as long as tibia; tibia with one retrolateral and one dorsal trichobothrium, posterior margin with seven retrolateral spines in a row, dorsally with two tongue-shaped apophyses, densely covered with teeth; paracymbium hook-shaped, distal arm long, with slightly curved tip; tegulum with short transparent protegulum; distal suprategular apophysis sclerotized, with bifurcated tip, extends above apex of cymbium. Embolic division: tail piece long, slightly overlapping suprategulum; embolic membrane transparent, distal end broad; anterior radical process arc-shaped, sclerotized, as long as embolus, distal end slightly frayed; embolus arc-shaped, sclerotized, thick.

Female (allotype, HNDWS-18-04 02)

Body. Total length 2.04. Carapace 0.86 long, 0.71 wide, yellowish, cephalic region slightly elevated (Fig. 5A); fovea, cervical and radial grooves distinct (Fig. 5A); clypeus 0.21 high. Sternum wider than long, yellowish, with spine-like hairs; labium wider than long; maxillae long, distal end broader, with scopulae (Fig. 5B). Chelicerae with five promarginal and four retromarginal teeth. Ocular region narrow, AER recurved, PER procurved, PER slightly wider. Eye sizes and interdistances: AME 0.05; ALE 0.07; PME 0.06; PLE 0.06; AME-AME 0.02; PME-PME 0.05; AME-ALE 0.03; PME-PLE 0.03; AMEPME 0.07; ALE-ALE 0.27; PLE-PLE 0.31; ALE-PLE 0.01. Length of legs: I, 2.2 (0.67, 0.77, 0.45, $0.31)$; II, 1.89 (0.59, 0.68, 0.36, 0.26); III, 1.72 (0.51, 0.57, 0.39, 0.25); IV, 2.24 (0.73, 0.77, 0.43, 0.31). Leg formula IV-I-II-III. TmI 0.17 and TmIV 0.12. Tibial spine formula: 1-1-1-1. Abdomen 1.18 long, 0.81 wide, all the other morphological characters similar to those of male (Fig. 5A-B).

EpIGYNe (Figs 3-4). Ventral plate concave, covered with thick setae; posterior margin of dorsal plate with round scapus; copulatory openings present between dorsal and ventral plate; copulatory ducts long, column-shaped; spermathecae kidney-shaped, pointing towards scapus, separated by a distance of twothirds of their diameter; fertilization ducts small, extending mesally.

\section{Distribution}

Known only from the type locality (Fig. 11).

Yuelushannus barbatus sp. nov. urn:1sid:zoobank.org:act:1BE73953-9370-49F4-B90F-2F2F9E5DB15A

Figs 6-11

\section{Etymology}

The species name comes from Latin adjective "barbatus" meaning "frayed" referring to the frayed or brush-like distal end of the anterior radical process in the male palp.

\section{Diagnosis}

This new species resembles Yuelushannus alatus sp. nov., as two-thirds of the male abdomen anteriorly has a very distinct scutum; cephalic lobe and pits distinct; both male and female abdomen with four sigillae. Tibial apophyses densely covered with teeth, paracymbium hook-shaped. Epigyne with columnshaped copulatory ducts (Figs 3-4, 8-9). It can be distinguished by:

General: In male, ocular region with thick spines in Y. barbatus sp. nov. (Fig. 5E-G), wing-like spines which cover most of PMEs in Y. alatus sp. nov. (Fig. 10A-B). 


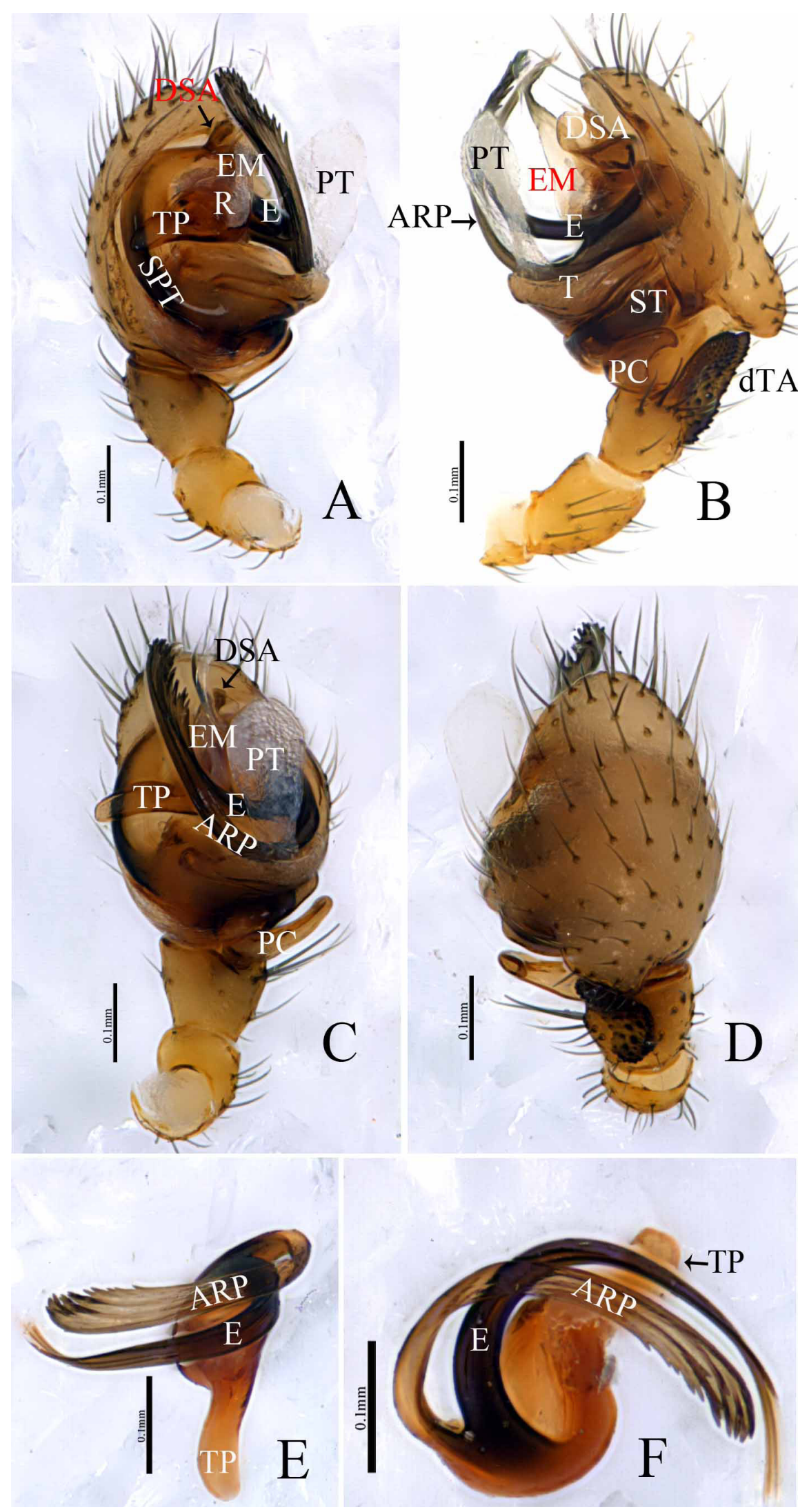

Fig. 6. Yuelushannus barbatus sp. nov., male palp, holotype YLS-17-0301 01. A. prolateral view. B. Retrolateral view. C. Ventral view. D. Dorsal view. E, F. Embolic division. Scale bars: $0.1 \mathrm{~mm}$ 
Male: Tibial apophyses long, almost touch proximal part of cymbium in Y. barbatus sp. nov. (Figs 1B, 2B), whereas the short, distal end does not touch the cymbium in Y. alatus sp. nov. (Figs 6B, 7B). Protegulum long, extends above the distal suprategular apophysis in Y. barbatus sp. nov. (Figs 1B, 2B), whereas it is short and below the distal suprategular apophysis in Y. alatus sp. nov. (Figs 6B, 7B). Distal suprategular apophysis short, tip not bifurcated (Figs 1A-B, 2), long, with bifurcated tip, extending above apex of cymbium in $Y$. alatus sp. nov. (Figs 6A-B, 7). Distal end of anterior radical process frayed in Y. barbatus sp. nov. (Figs 1A-B, 2), not frayed in Y. alatus sp. nov. (Figs 6A-B, 7).

Female: Spermathecae globular in Y. barbatus sp. nov.(Figs 3-4), kidney-shaped in Y. alatus sp. nov. (Figs 8-9).

\section{Holotype}

CHINA • ${ }^{\top}$; Hunan Province, Changsha City, Yuelu District, Yuelu Mountain; $28.19275^{\circ} \mathrm{N}, 112.9382^{\circ} \mathrm{E}$; 1 Mar. 2017; alt. 208 m; Zhou Gu-chun leg.; HNU-YLS-17-0301 01.
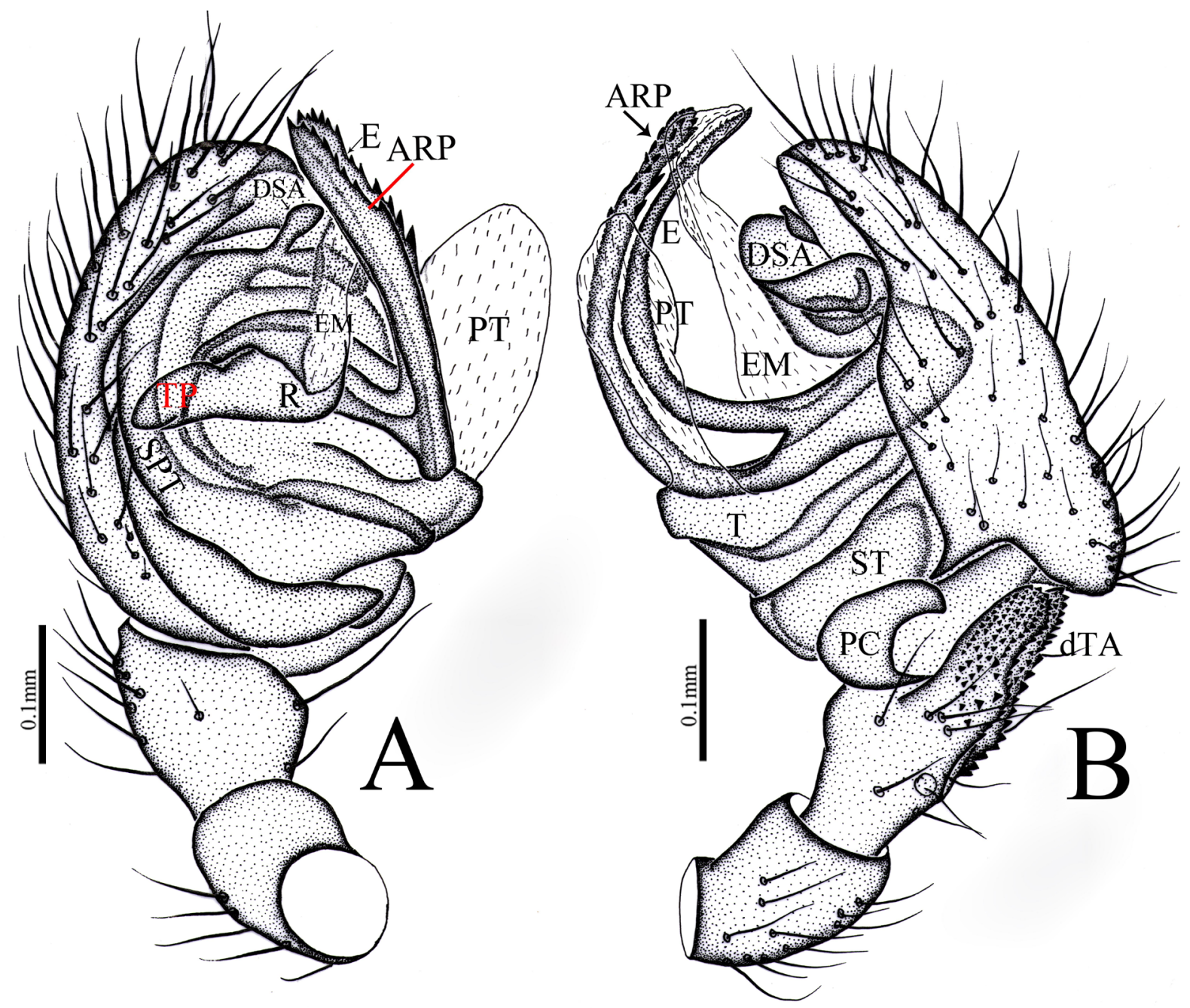

Fig. 7. Yuelushannus barbatus sp. nov., male palp, holotype (HNU-YLS-17-0301 01). A. Prolateral view. B. Retrolateral view. Scale bars: $0.1 \mathrm{~mm}$. 


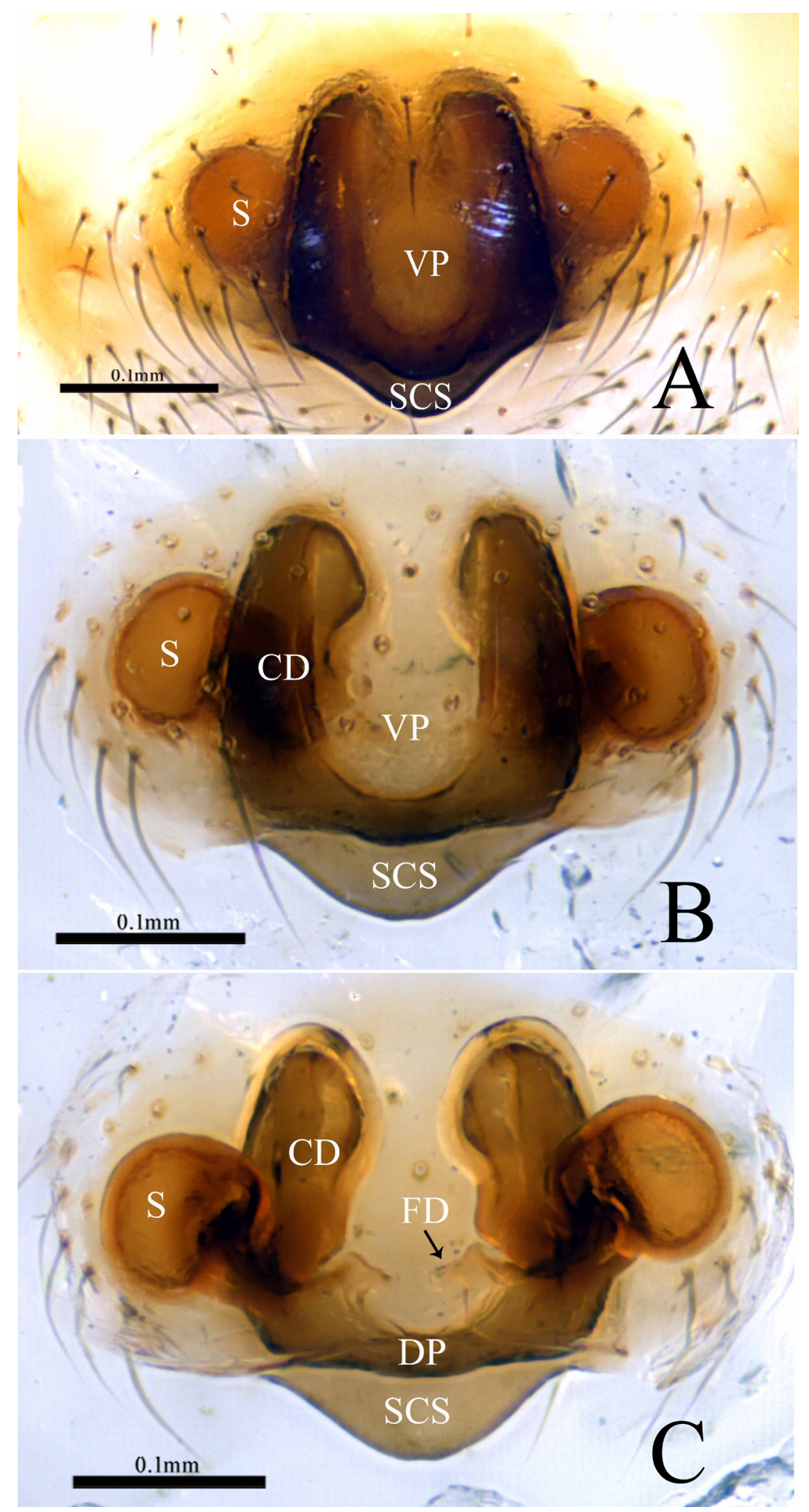

Fig. 8. Yuelushannus barbatus sp. nov., female, allotype (YLS-17-0301 02). A. Epigyne, ventral view (before being dissected from the body). B. Epigyne, ventral view (after being dissected from the body). C. Vulva, dorsal view. Scale bars: $0.1 \mathrm{~mm}$. 


\section{Paratypes}

CHINA - Hunan Province 1 1 , 10 우; same collection data as for holotype; HNU-YLS-17-0301 - 8 q o ; Changsha City, Yuelu District, Yuelu Mountain; $28.18475^{\circ} \mathrm{N}, 112.93112^{\circ} \mathrm{E}$; 8 Dec. 2016; alt. 280 m; Zhou Gu-chun leg.; HNU-YLS-16-1211 • 54 $\widehat{\jmath}, 60$ 우; Ningxiang City, Huaminglou Town,
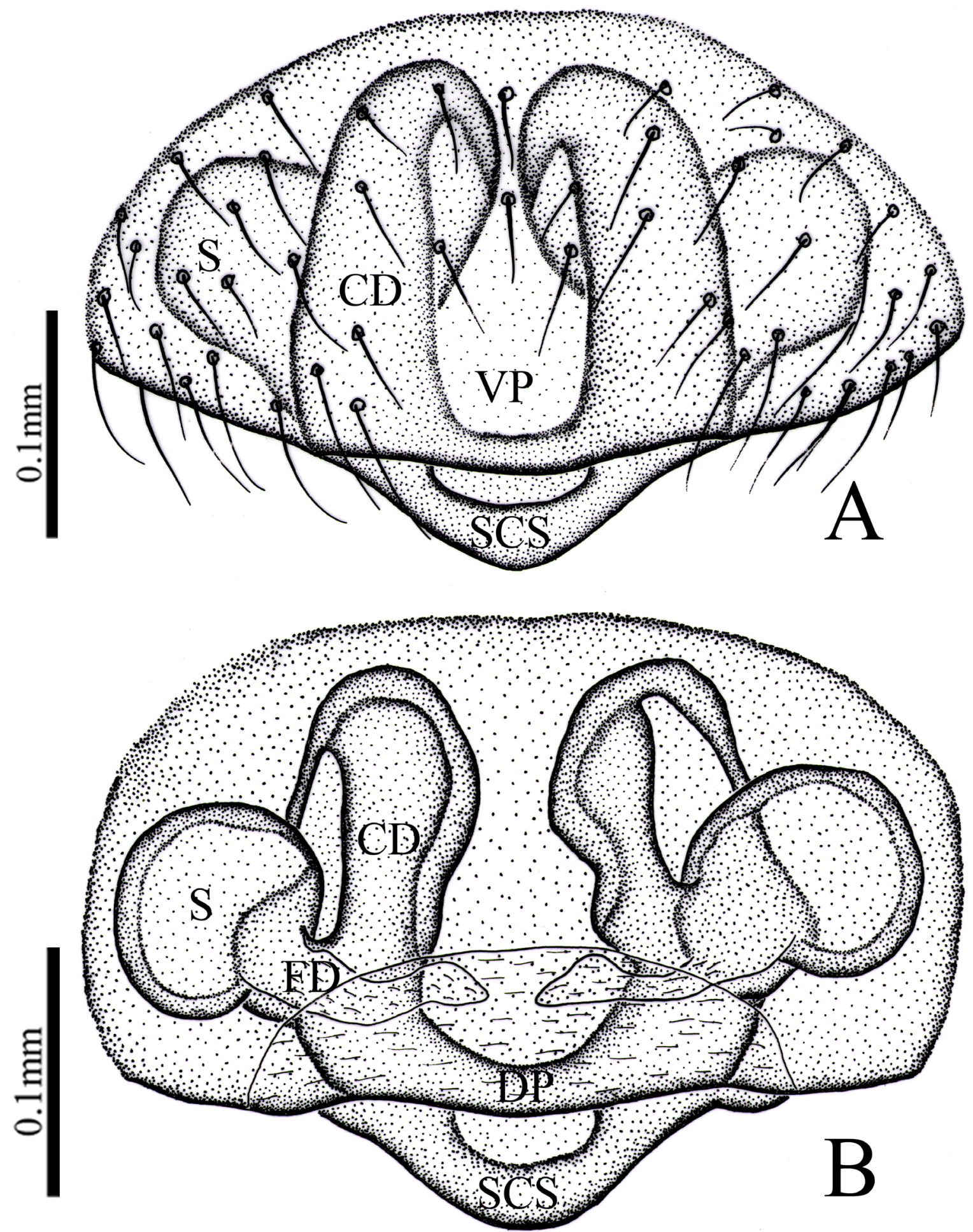

Fig. 9. Yuelushannus barbatus sp. nov., female, allotype (HNU-YLS-17-0301 02). A. Epigyne, ventral view. B. Vulva, dorsal view. Scale bars: $0.1 \mathrm{~mm}$. 
Jinyuan Village; $28.1002^{\circ}$ N, $112.5277^{\circ}$ E; 24 Oct. 2017; alt. 187 m; Zhou Gu-chun leg.; HNU-HNIV-1755 • 1 O; Ningxiang City, Huaminglou Town, Shili Village; $28.09035^{\circ} \mathrm{N}, 112.6670^{\circ} \mathrm{E}$; 9 May

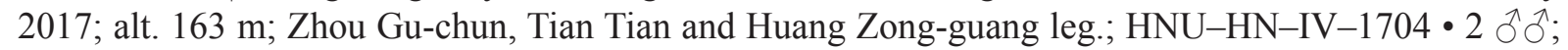
Ningxiang City, Huaminglou Town, Jinyuan Village; $28.10046^{\circ} \mathrm{N}, 112.66057^{\circ}$ E; 12 May 2017; alt. 209 m; Zhou Guchun, Tian Tian and Huang Zongguang leg.; HNU-HN-IV-1779・14 o $\circ$; Ningxiang County, Huaminglou Town, Yanglin Village; $28.10020^{\circ} \mathrm{N}, 112.65881^{\circ} \mathrm{E} ; 10$ May 2017; alt. $189 \mathrm{~m}$; Zhou Guchun, Tian Tian and Huang Zong-guang leg.; HNU-HN-IV-1707 • 1 q; Ningxiang City, Huaminglou Town, Shili Viollage; 28.08727 ${ }^{\circ}$ N, 112.67114 E; 9 May 2017; alt. 125 m; Zhou Guchun, Tian Tian and Huang Zongguang leg.; HNU-HN-IV-1703 • 6 ภ $\widehat{\jmath}, 3$ 우; Huaihua City, Huitong County, Tuanhe Town, Diaotang Village, Yingzuijie National Nature Reserve; $26.90186^{\circ} \mathrm{N}, 109.93529^{\circ}$

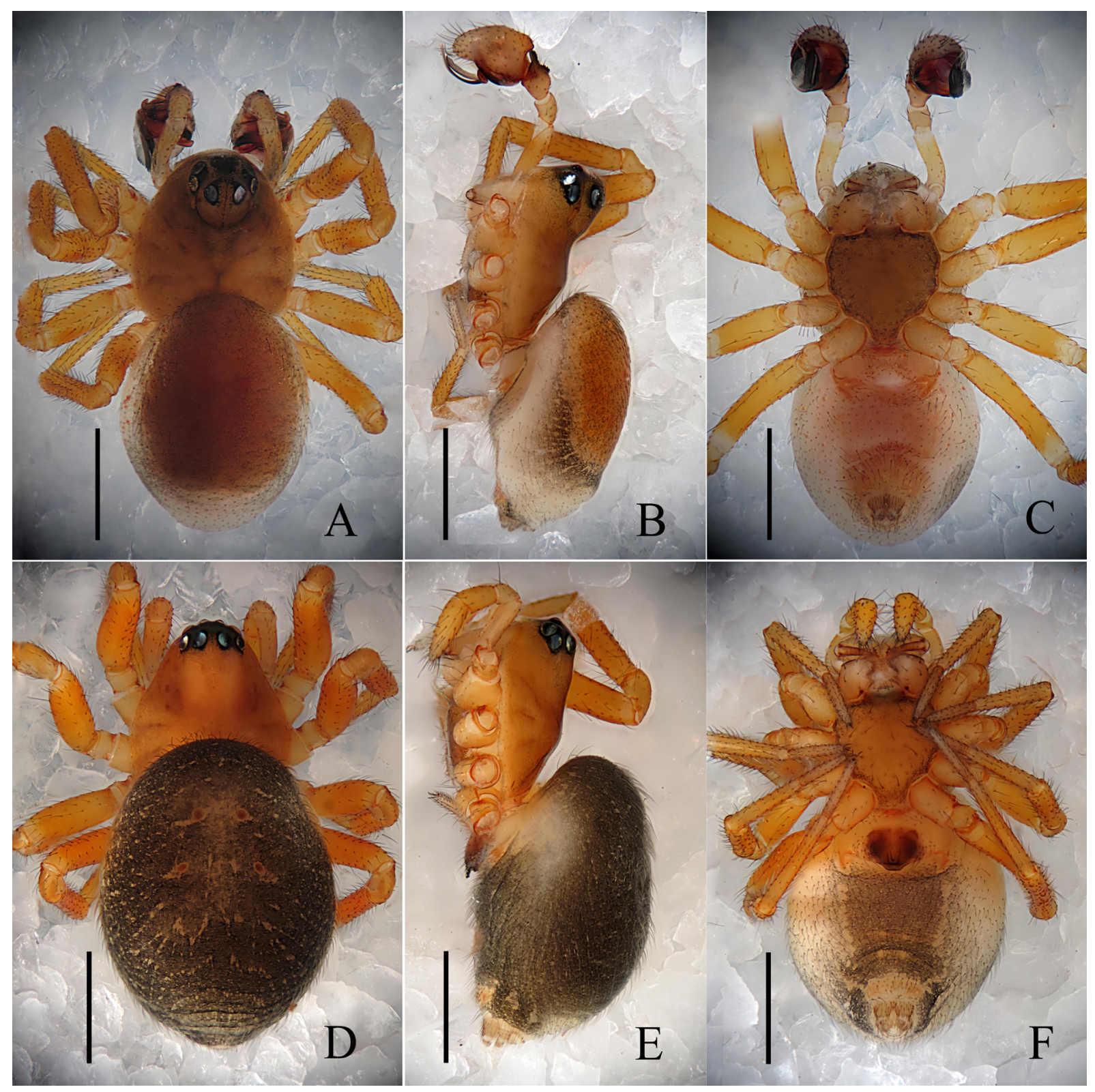

Fig. 10. Yuelushannus barbatus sp. nov., male, holotype, YLS-17-0301 01 (A-C) and female, allotype, YLS-17-0301 02 (D-F). A, D. Habitus, dorsal view. B, E. Habitus, lateral view. C, F. Habitus, ventral view. Scale bars: $0.5 \mathrm{~mm}$. 
E; alt. 390 m; Zhou Guchun, Tian Tian and Li Dengqin leg.; HNU-HN-IV-1767 • 1 ふૈ, 1 q; Huaihua City, Huitong County, Tuanhe Town, Xiangyan Village, Yingzuijie National Nature Reserve; $26.83700^{\circ}$ N, 109.88804 E; 28 Oct. 2017; alt. 684 m; Zhou Guchun leg.; HNU-HN-IV-1764. - Hubei Province - 2 ○ึ; Badong County, Yanduhe Town, Songziyuan Village; $31.3406^{\circ}$ N, $110.4131^{\circ}$ E; 26 Apr. 2016; alt. 1320 m; Liu Wang, Tian Tian and Ceng Chen leg.; HNU-HB-20160426.

\section{Description}

Male (holotype, HNU-YLS-17-0301 01)

Body. Total length 1.89. Carapace 0.88 long, 0.75 wide, brown, cephalic lobe 0.23 high, with distinct pits, ocular region with thick spines pointing away from each other (Fig. 10A-B), fovea, cervical and radial grooves distinct (Fig. 10A-B). Clypeus 0.28 high. Sternum wider than long, yellowish, with spine-like hairs; labium wider than long; maxillae long, distal end broader, with scopulae (Fig. 10C). Chelicerae with five promarginal and six retromarginal teeth. Ocular region narrow, AER straight, PER procurved, PME present on cephalic lobe. Eye sizes and interdistances: AME 0.05; ALE 0.08; PME 0.06; PLE 0.07; AME-AME 0.03; PME-PME 0.06; AME-ALE 0.03; PME-PLE 0.06; AME-PME 0.09; ALE-ALE 0.28; PLE-PLE 0.31; ALE-PLE contiguous. Length of legs: I, $2.4(0.68,0.84,0.53$, 0.35); II, 2.12 (0.62, 0.72, 0.46, 0.32); III, 1.81 (0.52, 0.61, 0.41, 0.27); IV, $2.46(0.71,0.87,0.56,0.32)$. Leg formula IV-I-II-III. TmI 0.24 and TmIV 0.18. Tibial spine formula: 1-1-1-1. Abdomen 1.12 long, 0.77 wide, round, anterior two-thirds of abdomen with distinct scutum and two pairs of sigillae, lateral sides dusky grey, ventral side pale (Fig. 10A-C).

PALP (Figs 6-7). Patella as long as tibia; tibia with a retrolateral and a dorsal trichobothrium, posterior margin with 5 spines in a row in retrolateral view, dorsally with two tongue-shaped apophyses densely covered with teeth, distal end almost touches cymbium; paracymbium U-shaped, distal arm with slightly curved tip; tegulum possess long transparent protegulum with broad distal end, extending above distal suprategular apophysis; distal suprategular apophysis sclerotized, slightly curved, with blunt distal end. Embolic division: tail piece long, slightly overlapping suprategulum; embolic membrane transparent, distal end broad; anterior radical process sclerotized, black, as long as embolus, distal end frayed or brush-like; embolus sclerotized, black, thick, distally curved, with blunt tip.

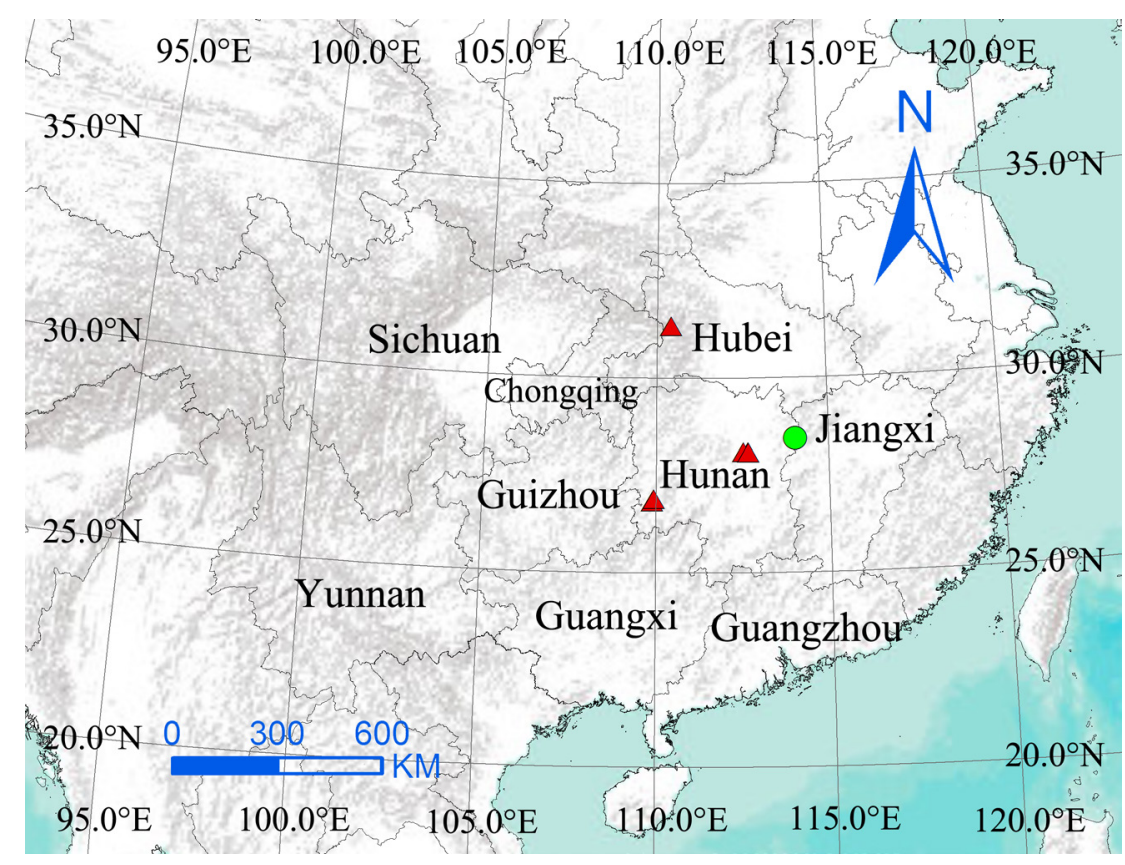

Fig. 11. Distribution of Yuelushannus alatus sp. nov. (green dot) and Y. barbatus sp. nov. (red triangles). 
Female (allotype, HNU-YLS-16-1211)

BoDy. Total length 2.19. Carapace 0.99 long, 0.80 wide, brown, with cephalic region slightly elevated; fovea, cervical and radial grooves distinct (Fig. 10D-E). Clypeus 0.29 high. Sternum wider than long, yellowish with spine-like hairs; labium wider than long; maxillae long, distal end broader, with scopulae (Fig. 10F). Chelicerae with five promarginal and six retromarginal teeth. Ocular region narrow, AER recurved, PER procurved, PER slightly wider. Eye sizes and interdistances: AME 0.06; ALE 0.09; PME 0.08; PLE 0.09; AME-AME 0.03; PME-PME 0.07; AME-ALE 0.02; PME-PLE 0.06; AME-PME 0.06; ALE-ALE 0.31; PLE-PLE 0.34; ALE-PLE contiguous. Length of legs: I, $2.49(0.73,0.85,0.55$, $0.36)$; II, 2.12 (0.67, 0.65, 0.48, 0.32); III, 1.88 (0.58, 0.63, 0.39, 0.28); IV, 2.67 (0.81, 0.96, 0.56, 0.34). Leg formula IV-I-II-III. TmI 0.21 and TmIV 0.16. Tibial spine formula: 1-1-1-1. Abdomen 1.28 long, 0.95 wide, round, grey with four sigillae, lateral sides dusky grey, ventral side grey (Fig. 10D, F).

EpIGYNe (Figs 8-9). Ventral plate sclerotized, concave, covered with thick spines; posterior margin of dorsal plate with round scapus; copulatory openings present between dorsal and ventral plate; copulatory ducts long, column-shaped; spermathecae globular, separated by a distance of $2 / 3$ of their diameter; fertilization ducts small, extending mesally.

\section{Distribution}

China (Hubei, Hunan, Fig. 11).

\section{Discussion}

Yuelushannus gen. nov. species were found to have the important diagnostic synapomorphies of erigonines, i.e., desmitracheate tracheal system; female palpal claw absent; male cephalic region with or without modification, pedipalp with tibial apophyses (Hormiga 2000; Locket \& Millidge 1953; Merrett 1963; Millidge 1951, 1977, 1984), but can be differentiated from all other erigoninae genera by the tibia with two tongue-shaped tibial apophyses densely provided with small teeth; anterior radical apophysis long, running parallel with embolus; dorsal plate of epigyne with scapus posteriorly and columnshaped copulatory ducts. On the basis of the presence of erigonine synapomorphies, we propose that Yuelushannus gen. nov. belongs to the family Linyphiidae.

\section{Acknowledgments}

We are grateful to Dr. Stephanie F. Loria (American Museum of Natural History, New York) for reviewing the English of this manuscript. We also thank Guo Tang and Peng Hu for collecting the specimens. This research was sponsored by the National Natural Sciences Foundation of China (NSFC-30970327, 31272271, 31272272, 31301861), National Special Fund on Basic Research of Science and Technology of China (No. 2014FY110100), the Hunan Provincial Program for Development of Key Disciplines in Ecology (grant number No. 0713), Hunan Provincial Natural Science Foundation of China (No.1 1JJ1004/12JJ3028/2018JJ3344), Program for New Century Excellent Talents in University (NCET12-0717), China Postdoctoral Science Foundation (No. 20100471221/201104506), the program of Hunan Provincial Science and Technology Plans (No. 2010RS4006) and Hunan Provincial Innovation Foundation for Postgraduates (No. CX2017B182).

\section{References}

Hormiga G. 2000. Higher level phylogenetics of erigonine spiders (Araneae, Linyphiidae, Erigoninae). Smithsonian Contributions to Zoology 609: 1-160.

Li S.Q. \& Lin Y.C. 2016. Species Catalogue of China, Volume 2, Animals, Invertebrates (I): Arachnida: Araneae. Science Press, Beijing. 
Locket G.H. \& Millidge A.F. 1953. British Spiders. Vol. II. Ray Society, London.

Merrett P. 1963. The palpus of male spiders of the family Linyphiidae. Proceedings of the Zoological Society of London 140 (3): 347-467. https://doi.org/10.1111/j.1469-7998.1963.tb01867.x

Millidge A.F. 1951. Key to the British genera of subfamily Erigoninae (Family Linyphiidae: Araneae): including the description of a new genus (Jacksonella). Annals and Magazine of Natural History 12, 4 (42): 545-562. https://doi.org/10.1080/00222935108654184

Millidge A.F. 1977. The conformation of the male palpal organs of linyphiid spiders, and its application to the taxonomic and phylogenetic analysis of the family (Araneae: Linyphiidae). Bulletin of the British Arachnological Society 4: 1-60.

Millidge A.F. 1984. The taxonomy of the Linyphiidae, based chiefly on the epigynal and tracheal characters (Araneae: Linyphiidae). Bulletin of the British Arachnological Society 6: 229-267.

Ono H., Matsuda M. \& Saito H. 2009. Linyphiidae, Pimoidae. In: Ono H. (ed.) The Spiders of Japan with Keys to the Families and Genera and Illustrations of the Species: 253-344. Tokai University Press, Kanagawa.

World Spider Catalog. 2019. World Spider Catalog. Natural History Museum Bern. Available from: http://wsc.nmbe.ch. ver. 20.0. [accessed on 25 June 2019].

Zhao, Q.Y. \& Li S.Q. 2014. A survey of linyphiid spiders from Xishuangbanna, Yunnan Province, China (Araneae, Linyphiidae). ZooKeys 460: 1-181. https://doi.org/10.3897/zookeys.460.7799

Manuscript received: 6 July 2019

Manuscript accepted: 13 December 2019

Published on: 7 May 2020

Topic editor: Rudy Jocqué

Desk editor: Marianne Salaün

Printed versions of all papers are also deposited in the libraries of the institutes that are members of the EJT consortium: Muséum national d'Histoire naturelle, Paris, France; Botanic Garden Meise, Belgium; Royal Museum for Central Africa, Tervuren, Belgium; Royal Belgian Institute of Natural Sciences, Brussels, Belgium; Natural History Museum of Denmark, Copenhagen, Denmark; Naturalis Biodiversity Center, Leiden, the Netherlands; Museo Nacional de Ciencias Naturales-CSIC, Madrid, Spain; Real Jardín Botánico de Madrid CSIC, Spain; Zoological Research Museum Alexander Koenig, Bonn, Germany; National Museum, Prague, Czech Republic. 